\title{
Dermatology
}

Dermatology 2016;232:633-639

DOI: $10.1159 / 000455840$
Received: November 16, 2016

Accepted after revision: January 3, 2017

Published online: February 23, 2017

\section{Psoriasis and Obesity}

\author{
Peter Jensen Lone Skov
}

Department of Dermatology and Allergy, Herlev and Gentofte Hospital, Hellerup, Denmark

\section{Keywords}

Obesity · Psoriasis · Nutritional care

\section{Abstract}

Psoriasis is a common chronic inflammatory skin disease with a complex pathogenesis consisting of a genetic component, immune dysfunction, and environmental factors. It is associated with numerous comorbidities including psoriatic arthritis, cardiovascular disease, metabolic syndrome, and obesity. Evidence suggests that obesity is a risk factor for incident psoriasis, aggravates existing psoriasis, and that weight reduction may improve the severity of psoriasis in overweight individuals. Excess body weight may interfere with the medical treatment used in psoriasis and adds to the cardiovascular risk profile in these patients, which underscores the importance of effective weight control regimens. In this review we examine the current literature with regard to the association between obesity and psoriasis.

(c) 2017 S. Karger AG, Basel

\section{Introduction}

Psoriasis is a common chronic inflammatory skin disease which affects $2-4 \%$ of the general population [1]. $\mathrm{Pa}$ tients with psoriasis have erythematous, scaly patches and plaques with a predilection for the scalp, lower back, elbows, and knees, but any part of the body may be affected [2]. Severe psoriasis has a great impact on quality of life, which is similar to that of insulin-dependent diabetes, de-

\section{KARGER}

E-Mail karger@karger.com www.karger.com/drm pression, and angina pectoris, but associated mortality rates are, of course, much lower [3]. Psoriasis is associated with a number of comorbidities; the most common is psoriatic arthritis, a potentially debilitating inflammatory arthritic condition affecting up to $34 \%$ of patients with psoriasis [4]. Furthermore, data from large registries have demonstrated an increased risk of skin cancer, lymphoma, diabetes, metabolic syndrome, obesity, venous thromboembolism, stroke, and myocardial infarction in patients with psoriasis [5-11]. The pathogenesis of psoriasis is thought to result from the interplay between a genetic component, immune dysfunction, and environmental factors [2]. The immune response in psoriasis is characterized by proliferation of Th1, Th17, and Th22 cells resulting in the production of the pro-inflammatory mediators interferon- $\gamma$, tumor necrosis factor (TNF)- $\alpha$, interleukin (IL)-6, and IL-22 [12, 13].

In recent decades, the prevalence of immune-mediated diseases in industrialized nations has been increasing, and also, there is evidence that the epidemiology of psoriasis seems to be changing $[14,15]$. For example, a 2009 US study demonstrated that the incidence of psoriasis among adults had almost doubled between the 1970s and 2000 [16]. Given the fact that the genetic basis has remained constant, awareness is increasing that factors in the environment including the Western lifestyle play a major role in this growing prevalence [17]. The dietary habits in industrialized nations promote high-fat, highsalt, high-sugar diets with excess caloric intake resulting in an obesity epidemic $[18,19]$. Obesity is a chronic condition characterized by excess body weight due to in-

Peter Jensen, MD, PhD

Department of Dermatology and Allergy Herlev and Gentofte Hospital

Kildegårdsvej 28, DK-2900 Hellerup (Denmark)

E-Mail peter.jensen@ regionh.dk 
creased energy deposits stored as body fat. When the equilibrium of food intake and energy expenditure is disturbed, regardless of the cause, this will result in either obesity or low body weight [20]. Obesity can be diagnosed by calculating the body mass index (BMI), which is the weight in kilograms divided by the square of the height in meters. The World Health Organization classifies BMI in adults as follows: a BMI between 18.5 and 24.9 is normal, 25-29 indicates overweight, and a BMI of more than 30 obesity [21, 22].

The possible link between autoimmunity and obesity has become even more relevant since the discovery that white adipose tissue is not just an inert energy storage tissue. It is now known that adipose tissue is an essential endocrine organ secreting a wide range of soluble mediators involved in immunity, inflammation, and metabolic and appetite regulation $[23,24]$. The soluble mediators released from white adipose tissue possess pro-inflammatory actions and contribute to the low-grade inflammatory state in obese individuals [23]. This pro-inflammatory state generated by obesity may be a key factor in the association between adiposity and inflammatory/autoimmune diseases which include rheumatoid arthritis, systemic lupus erythematosus, inflammatory bowel disease, multiple sclerosis, diabetes mellitus, and hidradenitis suppurativa $[25,26]$. In addition, recent research has focused on the regulatory role that innate lymphoid cells may play in obesity. Although little is known, innate lymphoid cells have been shown to perpetuate obesity-induced insulin resistance [27].

In psoriasis, epidemiological evidence is increasing and suggests that patients may be more adipose compared to individuals without psoriasis. Although the exact mechanisms underlying this association are at present unclear, researchers have hypothesized that adipocyte secretion of pro-inflammatory mediators may worsen psoriasis [28-32]. It seems, therefore, that the immunological mechanisms in psoriasis and obesity show considerable overlap. In this review, we shall focus on the current knowledge on the association between psoriasis and obesity, the inflammatory mediators linking the 2 conditions, and on the clinical implications.

\section{Association between Psoriasis and Obesity}

One of the first reports about the relationship between psoriasis and obesity came from Sweden in a study including 159,200 individuals who were followed up over a 10 -year period [33]. In the study, the authors found an association between women with psoriasis and obesity. In 1995, Henseler and Christophers [34] conducted a registry-based study including 42,461 individuals of whom $2,941(7 \%)$ had psoriasis and found a significantly higher prevalence of obesity in patients with psoriasis. More recently, a case-control study of 560 patients with psoriasis demonstrated that the risk of psoriasis in an overweight (BMI 26-29) or obese (BMI $\geq 30$ ) population was higher than in normal-weight individuals (odds ratio, OR, 1.6 and 1.9, respectively) [35]. Another registry-based study including 127,706 subjects with mild psoriasis (not receiving systemic therapy or phototherapy) and 3,854 persons with severe psoriasis (treated with systemic therapy or phototherapy) demonstrated a higher risk of obesity in those with severe psoriasis $(\mathrm{OR}, 1.8)$ than in those with mild psoriasis (OR, 1.3) [36]. Similar findings were made by another group in a study with 16,851 patients with psoriasis, which showed that patients under 35 years of age were more likely to be overweight $(\mathrm{OR}, 2.2)$ than those above the age of $65(\mathrm{OR}, 1.6)$ relative to healthy subjects [37]. It seems, therefore, that the association between psoriasis and obesity has been firmly established. Indeed, a meta-analysis of 16 observational studies including a total of 2.1 million subjects $(201,831$ with psoriasis) demonstrated that compared with individuals from the general population, patients with psoriasis are at significantly higher odds of obesity, with a pooled OR of 1.46 for mild psoriasis and an OR of 2.23 for severe psoriasis [11]. However, the direction of the relationship is still being debated, and current epidemiological evidence is inadequate to establish which comes first, psoriasis or obesity. Herron et al. [38] conducted a retrospective study and asked 557 patients with psoriasis about their body weight at the age of 18 and prior to the onset of psoriasis. At the same time, they asked the participants to record their current weight after the onset of psoriasis. Those who reported being overweight at the age of 18 did not have an increased risk for psoriasis, but the ones who went on to develop psoriasis had a higher propensity for obesity. The findings are suggestive of psoriasis occurring before obesity [38]. This notion is supported by the results of Mallbris et al. [39], who compared 200 patients within 12 months of onset of psoriasis to healthy controls and found no significant difference in BMI between the groups. In fact, the prevalence of obesity was higher in the control group (13\%) than in the group of patients with psoriasis (10\%) [39]. However, evidence strongly suggests that obesity is an independent risk factor for psoriasis. Supporting this hypothesis is a large prospective cohort study including 78,626 American female nurses followed for 14
634

Dermatology 2016;232:633-639

DOI: $10.1159 / 000455840$
Jensen/Skov 
years with 892 incident cases of psoriasis [40]. The study found a graded positive association between BMI measured at multiple time points and the risk of incident psoriasis. When $\mathrm{BMI}$, updated every 2 years, was analyzed and compared with a BMI of 21.0-22.9, the relative risks of psoriasis were 1.40 (95\% confidence interval, CI, 1.131.73) for a BMI of 25.0-29.9, 1.48 (95\% CI, 1.15-1.91) for a BMI of 30.0-34.9, and 2.69 (95\% CI, 2.12-3.40) for a BMI of 35.0 or greater $(p<0.001)$. For BMI at the age of 18 years, the relative risk for the top BMI category $(\geq 30.0)$ was 1.73 (95\% CI, 1.24-2.41), and that for a lower BMI category $(<21.0)$ was $0.76(95 \%$ CI, $0.65-0.90)(p<0.001)$. Weight gain from the age of 18 years, higher waist circumference, hip circumference, and waist-hip ratio were all associated with a higher risk of incident psoriasis [40]. In 2010, Bryld et al. [41] conducted a study exploring the temporal relationship between obesity and psoriasis. The study cohort included 309,152 school children and found that, for women, severe psoriasis resulting in hospitalization in adulthood was preceded by an increased BMI at the age of 12 .

\section{Inflammatory Mediators Linking Psoriasis and Obesity}

Numerous mechanisms may be involved in explaining the link between psoriasis and obesity. Patients with psoriasis may have a higher risk of social isolation, poor eating habits, depression, decreased physical activity, and increased alcohol consumption. Along those lines, Zamboni [42] showed that patients with psoriasis consumed significantly more fat, saturated fat, and alcohol compared to people without psoriasis. Also, obese patients with psoriasis exercise less than obese individuals without psoriasis [38]. Contributing to the increased risk of psoriasis in obese patients may be the shared chronic inflammatory state. Adipose tissue is the most effective lipid storage organ in the body besides providing mechanical protection and insulation. Obesity can be defined as the expansion of white adipose tissue, and the obese state is characterized by increased release of free fatty acids from white adipocytes, which in turn leads to elevated serum fatty acid levels. Indeed, dysregulation caused by obesity is a key component in the pathogenesis of the many diseases surrounding obesity including psoriasis. Adipocytes and cells residing within the adipose tissue secrete various soluble mediators involved in regulating organ function, metabolism, immunity, and inflammation. Therefore, adipose tissue can be classified as an endocrine

Psoriasis and Obesity
Table 1. Biological effects and regulation of major adipokines in the obese state

\begin{tabular}{lll}
\hline & Obesity & Biological effects \\
\hline Adiponectin & $\downarrow$ & $\begin{array}{l}\text { Appetite } \uparrow \\
\text { Insulin sensitivity } \uparrow \\
\text { Glucose uptake by white adipose tissue } \\
\text { and skeletal muscle } \uparrow \\
\text { Oxidation of free fatty acid in liver and } \\
\text { skeletal muscle } \uparrow\end{array}$ \\
\hline Leptin & $\uparrow$ & $\begin{array}{l}\text { Resting energy expenditure } \uparrow \\
\text { Lipolysis } \uparrow \\
\text { Hepatic lipogenesis } \downarrow\end{array}$ \\
\hline Resistin & $\uparrow$ & $\begin{array}{l}\text { Insulin resistance } \uparrow \\
\text { Free fatty acid release by white adipose } \\
\text { tissue } \uparrow\end{array}$ \\
\hline Visfatin & $\uparrow$ & Probably insulin-like effects \\
\hline
\end{tabular}

organ which plays a pivotal role in regulating the metabolic homeostasis of healthy subjects $[23,43]$. The mediators secreted by adipose tissue, named adipokines, possess pro-inflammatory capabilities and contribute to the low-grade inflammatory state in obese individuals resulting in a range of comorbidities including cardiovascular disease, diabetes, and the metabolic syndrome [23, 26].

Several studies have demonstrated that white adipose tissue is a crucial site in the formation of pro-inflammatory adipokines which include the classical cytokines such as IL- 6 , TNF- $\alpha$, and the specific molecules leptin, adiponectin, and resistin (Table 1) [23]. In fact, leptin is largely produced by white adipose tissue, plasma levels of leptin correlate directly with body fat mass and adipocyte size. Its synthesis is downregulated by testosterone, glucocorticoids, and starvation and upregulated by inflammatory mediators (TNF- $\alpha$, IL-1 $\beta$ ), insulin, and ovarian sex hormones. Leptin acts on specific hypothalamic nuclei and is a crucial regulator of body weight by promoting satiety and increasing energy expenditure. It is also a potent immune modulator pushing both innate and acquired immunity toward a pro-inflammatory profile. Like leptin, adiponectin is mainly secreted by white adipose tissue. Plasma levels of adiponectin are increased with weight loss and decreased in obesity. It is an important regulator of metabolism and energy homeostasis, enhancing insulin sensitivity and decreasing hepatic glycogenesis. Furthermore, adiponectin promotes glucose uptake in skeletal muscle and in adipose tissue as well as

Dermatology 2016;232:633-639 DOI: $10.1159 / 000455840$ 
increasing hepatic and muscle tissue free fatty acid oxidation. In contrast to leptin, adiponectin is an anti-inflammatory adipokine [26]. In humans, resistin is largely produced by circulating and white adipose tissue-resident peripheral blood mononuclear cells. Levels of resistin increase with obesity and, although controversial, high circulating levels have been associated with increased obesity, type 2 diabetes and insulin resistance. Recently it has been demonstrated that adiposity may lead to induction of T-helper 17 cells (Th17). Th17 cells secrete IL-17 and are recognized for the involvement in the pathogenesis of autoimmune diseases including psoriasis [26]. Also, it is possible that the contribution of nutrients, in particular a high-salt, high-fat diet, may play a role in immune-mediated conditions. It is speculated that a Western diet may result in an alteration of the intestinal microbiome which may then induce modulation of extraintestinal immune responses with effects on the Th17/ $\mathrm{T}_{\text {regulatory }}$ balance [4446]. Psoriasis is characterized by proliferation of Th1, Th17, and Th22 cells resulting in the production of the pro-inflammatory mediators interferon- $\gamma$, TNF- $\alpha$, IL- 6 , and IL-22 $[12,13]$. Therefore, TNF- $\alpha$ and IL- 6 secreted by adipose tissue may contribute to the inflammatory state in psoriasis [47]. With regard to leptin and resistin, several studies have found high levels of both of these adipokines in obese individuals with psoriasis and that plasma concentrations correlated with the severity of psoriasis $[13,31,48-50]$. Also, it has been demonstrated that resistin levels decreased under treatment [50-52]. A recent meta-analysis including 11 studies showed that patients with psoriasis have higher levels of leptin compared to persons without psoriasis [13]. Both resistin and leptin promote the secretion of TNF- $\alpha$ and IL- 8 which are involved in the pathogenesis of psoriasis. Also, tissue levels of leptin are increased in the skin of patients with psoriasis, and here it stimulates secretion of pro-inflammatory cytokines in vitro $[53,54]$. The role of adiponectin in psoriasis is more uncertain. Several studies have suggested that lower levels are found in patients with psoriasis which correlate inversely with the severity of psoriasis $[29,55,56]$. However, evidence is conflicting as a recent meta-analysis found no difference between adiponectin levels in patients with psoriasis and controls [57]. At this point, it is reasonable to wonder whether perhaps there may be a common genetic predisposition for developing both psoriasis and obesity or through which mechanisms the presence of obesity might predispose to psoriasis and vice versa. We know that HLA-Cw6, a major psoriasis susceptibility gene, is also associated with obesity. Obese patients with the HLA-Cw6 gene were 35 times more like- ly to develop psoriasis than patients of normal weight without the HLA-Cw6 gene [58]. In normal-weight individuals with HLA-Cw6 positivity the risk of psoriasis was 8.33 times greater than for persons with HLA-Cw6 negativity [58]. Studies have shown that psoriasis is mainly associated with central adiposity reflected in an increased waist-to-hip ratio $[40,58]$. Since it is clear that psoriasis and obesity may coexist, it is possible that there is an interaction between the 2 diseases, and therefore adipokines may play a regulatory and shared role.

\section{Impact of Obesity on the Treatment of Psoriasis}

There are numerous difficulties when treating obese patients with psoriasis. Obesity has been associated with a decreased response to systemic and biological treatment. Also, obesity is associated with certain conditions such as metabolic syndrome and hepatic steatosis which may increase the risk of adverse treatment effects. Treatment cost is potentially also affected by obesity when drugs are prescribed in weight-adjusted doses.

Treatment with methotrexate (MTX) may be complicated by obesity since nonalcoholic hepatic steatosis can contribute to the hepatotoxicity of MTX. In fact, studies have shown that, in overweight patients with psoriasis treated with MTX, obesity is a greater risk factor for hepatotoxicity than viral hepatitis, alcohol, and cumulative dose of MTX. Steatosis of the liver probably adds to the risk, and therefore liver transaminases should be monitored more closely in these patients [59-61]. Little is known about the effect of obesity on the response to treatment with MTX, but 1 study showed that loss of response over time was more likely in obese patients treated with MTX [62].

Cyclosporine is a highly lipophilic drug which binds to lipoproteins that generally are present in larger quantities in overweight individuals. The relationship between obesity and serum concentrations of cyclosporine has been investigated in 16 patients with psoriasis [63]. The study found a positive correlation between the standardized trough concentration and obesity demonstrating that for a given dose of cyclosporine, obese persons are more likely than nonadipose subjects to have increased serum levels and as a consequence, nephrotoxicity. Other studies have shown that obesity is a risk factor for adverse events in patients treated with cyclosporine, especially if other risk factors are present, such as advanced age, concomitant use of nephrotoxic drugs, and hypertension. In such cases, the cyclosporine should be dosed according to ideal weight and not actual weight [64]. Interestingly, adi-
636

Dermatology 2016;232:633-639

DOI: $10.1159 / 000455840$
Jensen/Skov 
posity also appears to affect the effectiveness of treatment with cyclosporine on the severity of psoriasis. Gisondi et al. [65] demonstrated that moderate weight reduction (5$10 \%$ of body weight) increased the response to low-dose cyclosporine in patients with psoriasis compared to a control group.

In psoriasis, treatment with acitretin is often associated with hypercholesterolemia with decreased highdensity lipoprotein. Corbetta et al. [32] studied the effects of acitretin on lipid metabolism after 1 and 3 months of treatment with acitretin in 10 patients with psoriasis and found only transient changes in lipid and glucose metabolism which were not associated with changes in BMI.

Adipose tissue can be considered an endocrine organ which actively secretes fatty acids, hormones (leptin, adiponectin), and pro-inflammatory cytokines (TNF- $\alpha$, IL1, IL-6, IL-10). TNF- $\alpha$ inhibitors are meant to eliminate excess TNF- $\alpha$ from the psoriatic plaques and the circulation, and since TNF- $\alpha$ production is increased in adiposity, these drugs may be less effective in obese patients [66, 67]. In fact, Naldi et al. [68] published a study which analyzed data from a number of clinics with data from patients with psoriasis treated with biologicals. The study showed that the BMI was a predictor for treatment response in the sense that the proportion of patients who achieved a 75\% reduction of the Psoriasis Area and Severity Index (PASI) decreased with an increasing BMI. It is worth noting that studies have shown that biological treatment may lead to increased body weight in patients with moderate to severe psoriasis, a phenomenon that may be mediated by a reduced release of leptin which in turn causes hyperphagia $[69,70]$.

\section{Effect of Weight Reduction on the Severity of Psoriasis}

Data from case reports of overweight patients with psoriasis undergoing weight reduction surgery suggest that psoriasis may improve with weight loss although data are conflicting [71-76]. A recent review on the impact of weight loss intervention found that losing weight through decreased caloric intake reduced the severity of psoriasis by a PASI score of about 2.5 [77]. In 2013, we published the results of a randomized trial including 60 obese patients with psoriasis [78]. Those in the intervention group were randomized to a low-calorie diet, lost $15 \mathrm{~kg}$ more than the controls, and experienced a greater mean reduction in their PASI than controls (mean PASI reduction $-2.3 ; p=0.06)$. Furthermore, we showed that the weight

Psoriasis and Obesity loss and the beneficial effect on the severity of psoriasis were largely maintained after 1 year [79]. In a similar fashion, Naldi et al. [80] have recently randomized obese patients with psoriasis to receive either a dietary plan and physical exercise or simple counseling. After the study, there was a significant improvement of psoriasis severity in the intervention arm compared to controls with a PASI reduction of $48 \%$ versus $25.5 \%$. Thus, evidence is strongly suggestive of a pathogenic role of obesity on both the occurrence and severity of psoriasis.

\section{Conclusion}

Evidence is strongly suggestive that obesity, through pro-inflammatory pathways, predisposes to the development of psoriasis and that obesity aggravates existing psoriasis. While larger, randomized trials are needed to fully elucidate the potential effect of weight reduction on the severity of psoriasis, current knowledge supports the necessity of nutritional care as part of the management of psoriasis, in particular as weight loss has a substantial and positive effect on the cardiovascular risk profile in these patients. Also, treating overweight patients with psoriasis imposes certain problems such as increased risk of adverse events, reduced efficacy of biologicals, and higher treatment costs, which further underscore that weight reduction in these patients should be one of the aims of their management.

\section{Disclosure Statement}

The authors have no conflicts of interest to disclose. There was no funding for this work.

References

1 Christophers E: Psoriasis - epidemiology and clinical spectrum. Clin Exp Dermatol 2001; 26:314-320.

2 Griffiths CEM, Barker JNWN: Pathogenesis and clinical features of psoriasis. Lancet 2007; 370:263-271.

3 Grozdev I, Kast D, Cao L, Carlson D, Pujari P, Schmotzer B, et al: Physical and mental impact of psoriasis severity as measured by the compact Short Form-12 Health Survey (SF12) quality of life tool. J Invest Dermatol 2012; 132:1111-1116

4 Gladman DD, Antoni C, Mease P, Clegg DO Nash P: Psoriatic arthritis: epidemiology, clinical features, course, and outcome. Ann Rheum Dis 2005;64(suppl 2):ii14-ii17. 
5 Margolis D, Bilker W, Hennessy S, Vittorio C, Santanna J, Strom BL: The risk of malignancy associated with psoriasis. Arch Dermatol 2001;137:778-783.

6 Gelfand JM, Berlin J, Van Voorhees A, Margolis DJ: Lymphoma rates are low but increased in patients with psoriasis: results from a population-based cohort study in the United Kingdom. Arch Dermatol 2003;139:14251429.

7 Khalid U, Hansen PR, Gislason GH, Lindhardsen J, Kristensen SL, Winther SA, et al: Psoriasis and new-onset diabetes: a Danish nationwide cohort study. Diabetes Care 2013; 36:2402-2407.

8 Ungprasert P, Sanguankeo A, Upala S, Suksaranjit $\mathrm{P}$ : Psoriasis and risk of venous thromboembolism: a systematic review and metaanalysis. Q J Med 2014;107:793-797.

$9 \mathrm{Xu} \mathrm{T}$, Zhang Y-H: Association of psoriasis with stroke and myocardial infarction: metaanalysis of cohort studies. Br J Dermatol 2012; 167:1345-1350.

10 Armstrong AW, Harskamp CT, Armstrong EJ: Psoriasis and metabolic syndrome: a systematic review and meta-analysis of observational studies. J Am Acad Dermatol 2013;68: 654-662.

11 Armstrong AW, Harskamp CT, Armstrong EJ: The association between psoriasis and obesity: a systematic review and meta-analysis of observational studies. Nutr Diabetes 2012;2:e54.

12 Michalak-Stoma A, Pietrzak A, Szepietowski JC, Zalewska-Janowska A, Paszkowski T, Chodorowska G: Cytokine network in psoriasis revisited. Eur Cytokine Netw 2011;22:160168.

13 Zhu K-J, Zhang C, Li M, Zhu C-Y, Shi G, Fan Y-M: Leptin levels in patients with psoriasis: a meta-analysis. Clin Exp Dermatol 2013;38: 478-483.

14 Pedersen JK, Svendsen AJ, Hørslev-Petersen $\mathrm{K}$ : Incidence of rheumatoid arthritis in the southern part of Denmark from 1995 to 2001. Open Rheumatol J 2007;1:18-23.

15 Patterson CC, Dahlquist GG, Gyürüs E, Green A, Soltész G: Incidence trends for childhood type 1 diabetes in Europe during 1989-2003 and predicted new cases 2005-20: a multicentre prospective registration study. Lancet 2009;373:2027-2033.

16 Icen M, Crowson CS, McEvoy MT, Dann FJ, Gabriel SE, Maradit Kremers H: Trends in incidence of adult-onset psoriasis over three decades: a population-based study. J Am Acad Dermatol 2009;60:394-401.

17 Moroni L, Bianchi I, Lleo A: Geoepidemiology, gender and autoimmune disease. Autoimmun Rev 2012;11:A386-A392.

18 Flegal KM: Prevalence and trends in obesity among US adults, 1999-2008. JAMA 2010; 303:235.

19 World Health Organization: Overweight/ obesity: overweight by country. Global Health Observatory Data Repository 2008-2013. Geneva, WHO, 2013.
20 Samaras K, Kelly PJ, Chiano MN, Spector TD, Campbell LV: Genetic and environmental influences on total-body and central abdominal fat: the effect of physical activity in female twins. Ann Intern Med 1999;130:873-882.

21 WHO: Physical status: the use and interpretation of anthropometry. Report of a WHO Expert Committee. WHO Technical Report Series 854. Geneva, World Health Organization, 1995. http://whqlibdoc.who.int/trs/ WHO_TRS_854.pdf.

22 The World Health Report 2002: reducing risks, promoting healthy life. Geneva, World Health Organization, 2002.

23 Cao H: Adipocytokines in obesity and metabolic disease. J Endocrinol 2014;220:T47T59.

24 Gómez R, Conde J, Scotece M, Gómez-Reino JJ, Lago F, Gualillo O: What's new in our understanding of the role of adipokines in rheumatic diseases? Nat Rev Rheumatol 2011;7: 528-536.

25 Miller IM, Ellervik C, Yazdanyar S, Jemec GBE: Meta-analysis of psoriasis, cardiovascular disease, and associated risk factors. J Am Acad Dermatol 2013;69:1014-1024.

26 Versini M, Jeandel P-Y, Rosenthal E, Shoenfeld Y: Obesity in autoimmune diseases: not a passive bystander. Autoimmun Rev 2014;13: 981-1000.

27 Yang D, Yang W, Tian Z, van Velkinburgh JC, Song J, Wu Y, et al: Innate lymphoid cells as novel regulators of obesity and its associated metabolic dysfunction. Obes Rev 2016;17: 485-498.

28 Wellen KE, Hotamisligil GS: Inflammation, stress, and diabetes. J Clin Invest 2005;115: 1111-1119.

29 Shibata S, Saeki H, Tada Y, Karakawa M, Komine M, Tamaki K: Serum high molecular weight adiponectin levels are decreased in psoriasis patients. J Dermatol Sci 2009;55:62-63.

30 Coimbra S, Oliveira H, Reis F, Belo L, Rocha S, Quintanilha A, et al: Circulating levels of adiponectin, oxidized LDL and C-reactive protein in Portuguese patients with psoriasis vulgaris, according to body mass index, severity and duration of the disease. J Dermatol Sci 2009;55:202-204

31 Wang Y, Chen J, Zhao Y, Geng L, Song F, Chen H-D: Psoriasis is associated with increased levels of serum leptin. Br J Dermatol 2008;158:1134-1135.

32 Corbetta S, Angioni R, Cattaneo A, Beck-Pec$\operatorname{coz}$ P, Spada A: Effects of retinoid therapy on insulin sensitivity, lipid profile and circulating adipocytokines. Eur J Endocrinol 2006; 154:83-86.

33 Lindegård B: Diseases associated with psoriasis in a general population of 159,200 middleaged, urban, native Swedes. Dermatologica 1986;172:298-304.

34 Henseler T, Christophers E: Disease concomitance in psoriasis. J Am Acad Dermatol 1995. 32:982-986.

35 Naldi L, Chatenoud L, Linder D, Belloni Fortina A, Peserico A, Virgili AR, et al: Cigarette smoking, body mass index, and stressful life events as risk factors for psoriasis: results from an Italian case-control study. J Invest Dermatol 2005;125:61-67.

36 Neimann AL, Shin DB, Wang X, Margolis DJ, Troxel AB, Gelfand JM: Prevalence of cardiovascular risk factors in patients with psoriasis. J Am Acad Dermatol 2006;55:829-835.

37 Cohen AD, Sherf M, Vidavsky L, Vardy DA, Shapiro J, Meyerovitch J: Association between psoriasis and the metabolic syndrome. Dermatology 2008;216:152-155.

38 Herron MD, Hinckley M, Hoffman MS, Papenfuss J, Hansen CB, Callis KP, et al: Impact of obesity and smoking on psoriasis presentation and management. Arch Dermatol 2005; 141:1727-1534.

39 Mallbris L, Granath F, Hamsten A, Ståhle M: Psoriasis is associated with lipid abnormalities at the onset of skin disease. J Am Acad Dermatol 2006;54:614-621.

40 Setty AR, Curhan G, Choi HK: Obesity, waist circumference, weight change, and the risk of psoriasis in women: Nurses' Health Study II. Arch Intern Med 2007;167:1670-1675.

41 Bryld LE, Sørensen TI, Andersen KK, Jemec GB, Baker JL: High body mass index in adolescent girls precedes psoriasis hospitalization. Acta Derm Venereol 2010;90:488-493.

42 Zamboni S, Zanetti G, Grosso G, Ambrosio GB, Gozzetti S, Peserico A: Dietary behaviour in psoriatic patients. Acta Derm Venereol Suppl (Stockh) 1989;146:182-183.

43 Brembilla NC, Boehncke W-H: Dermal adipocytes' claim for fame in psoriasis. Exp Dermatol 2016, Epub ahead of print.

44 Van der Meer JWM, Netea MG: A salty taste to autoimmunity. N Engl J Med 2013;368: 2520-2521.

45 Manzel A, Muller DN, Hafler DA, Erdman SE, Linker RA, Kleinewietfeld M: Role of "western diet" in inflammatory autoimmune diseases. Curr Allergy Asthma Rep 2014;14:404.

46 Brown K, DeCoffe D, Molcan E, Gibson DL: Diet-induced dysbiosis of the intestinal microbiota and the effects on immunity and disease. Nutrients 2012;4:1095-1119.

47 Bulló M, García-Lorda P, Megias I, Salas-Salvadó J: Systemic inflammation, adipose tissue tumor necrosis factor, and leptin expression. Obes Res 2003;11:525-531.

48 Johnston A, Arnadottir S, Gudjonsson JE, Aphale A, Sigmarsdottir AA, Gunnarsson SI, et al: Obesity in psoriasis: leptin and resistin as mediators of cutaneous inflammation. $\mathrm{Br} \mathrm{J}$ Dermatol 2008;159:342-350.

49 Coimbra S, Oliveira H, Reis F, Belo L, Rocha S, Quintanilha A, et al: Circulating adipokine levels in Portuguese patients with psoriasis vulgaris according to body mass index, severity and therapy. J Eur Acad Dermatol Venereol 2010;24:1386-1394.

50 Takahashi H, Tsuji H, Honma M, Ishida-Yamamoto A, Iizuka H: Increased plasma resistin and decreased omentin levels in Japanese patients with psoriasis. Arch Dermatol Res 2013;305:113-116. 
51 Özdemir M, Yüksel M, Gökbel H, Okudan N, Mevlitoğlu İ: Serum leptin, adiponectin, resistin and ghrelin levels in psoriatic patients treated with cyclosporin. J Dermatol 2012;39: 443-448.

52 Kawashima K, Torii K, Furuhashi T, Saito C, Nishio E, Nishida E, et al: Phototherapy reduces serum resistin levels in psoriasis patients. Photodermatol Photoimmunol Photomed 2011;27:152-155.

53 Çerman AA, Bozkurt S, Sav A, Tulunay A, Elbaşı MO, Ergun T: Serum leptin levels, skin leptin and leptin receptor expression in psoriasis. Br J Dermatol 2008;159:820-826.

54 Xue K, Liu H, Jian Q, Liu B, Zhu D, Zhang M, et al: Leptin induces secretion of pro-inflammatory cytokines by human keratinocytes in vitro - a possible reason for increased severity of psoriasis in patients with a high body mass index. Exp Dermatol 2013;22:406-410.

55 Shibata S, Tada Y, Hau C, Tatsuta A, Yamamoto M, Kamata M, et al: Adiponectin as an anti-inflammatory factor in the pathogenesis of psoriasis: induction of elevated serum adiponectin levels following therapy. Br J Dermatol 2011;164:667-670.

56 Takahashi H, Tsuji H, Takahashi I, Hashimoto $\mathrm{Y}$, Ishida-Yamamoto A, Iizuka H. Plasma adiponectin and leptin levels in Japanese patients with psoriasis. Br J Dermatol 2008;159: 1207-1208

57 Zhu K-J, Shi G, Zhang C, Li M, Zhu C-Y, Fan Y-M: Adiponectin levels in patients with psoriasis: a meta-analysis. J Dermatol 2013;40: 438-442.

58 Jin Y, Zhang F, Yang S, Kong Y, Xiao F, Hou $Y$, et al: Combined effects of HLA-Cw6, body mass index and waist-hip ratio on psoriasis vulgaris in Chinese Han population. J Dermatol Sci 2008;52:123-129.

59 Berends MAM, Snoek J, de Jong EMGJ, van de Kerkhof PCM, van Oijen MGH, van Krieken $\mathrm{JH}$, et al: Liver injury in long-term methotrexate treatment in psoriasis is relatively infrequent. Aliment Pharmacol Ther 2006;24: 805-811.

60 Malatjalian DA, Ross JB, Williams CN, Colwell SJ, Eastwood BJ: Methotrexate hepatotoxicity in psoriatics: report of 104 patients from Nova Scotia, with analysis of risks from obesity, diabetes and alcohol consumption during long term follow-up. Can J Gastroenterol 1996;10:369-375.

61 Montaudié H, Sbidian E, Paul C, Maza A, Gallini A, Aractingi S, et al: Methotrexate in psoriasis: a systematic review of treatment modalities, incidence, risk factors and monitoring of liver toxicity. J Eur Acad Dermatol Venereol 2011;25:12-18.

62 Murray ML, Bergstresser PR, Adams-Huet B, Cohen JB: Relationship of psoriasis severity to obesity using same-gender siblings as controls for obesity. Clin Exp Dermatol 2009;34: 140-144.

63 Shibata N, Hayakawa T, Hoshino N, Minouchi T, Yamaji A, Uehara M: Effect of obesity on cyclosporine trough concentrations in psoriasis patients. Am J Health Syst Pharm 1998;55:1598-1602.

64 Maza A, Montaudié H, Sbidian E, Gallini A, Aractingi S, Aubin F, et al: Oral cyclosporin in psoriasis: a systematic review on treatment modalities, risk of kidney toxicity and evidence for use in non-plaque psoriasis. J Eur Acad Dermatol Venereol 2011;25:19-27.

65 Gisondi P, Del Giglio M, Di Francesco V, Zamboni M, Girolomoni G: Weight loss improves the response of obese patients with moderate-to-severe chronic plaque psoriasis to low-dose cyclosporine therapy: a randomized, controlled, investigator-blinded clinical trial. Am J Clin Nutr 2008;88:12421247.

66 Micha R, Imamura F, Wyler von Ballmoos M, Solomon DH, Hernán MA, Ridker PM, et al: Systematic review and meta-analysis of methotrexate use and risk of cardiovascular disease. Am J Cardiol 2011;108:1362-1370.

67 Ritchie SA, Connell JMC: The link between abdominal obesity, metabolic syndrome and cardiovascular disease. Nutr Metab Cardiovasc Dis 2007;17:319-326.

68 Naldi L, Addis A, Chimenti S, Giannetti A, Picardo M, Tomino C, et al: Impact of body mass index and obesity on clinical response to systemic treatment for psoriasis. Dermatology 2008;217:365-373.

69 Saraceno R, Schipani C, Mazzotta A, Esposito M, Di Renzo L, De Lorenzo A, et al: Effect of anti-tumor necrosis factor-alpha therapies on body mass index in patients with psoriasis. Pharmacol Res 2008;57:290-295.

70 Kofoed K, Clemmensen A, Mikkelsen UR, Simonsen L, Andersen O, Gniadecki R: Effects of anti-tumor necrosis factor therapy on body composition and insulin sensitivity in patients with psoriasis. Arch Dermatol 2012; 148:1089.

71 Pérez-Pérez L, Allegue F, Caeiro JL, Zulaica JMFA: Severe psoriasis, morbid obesity and bariatric surgery. Clin Exp Dermatol 2009; 34:e421-e422.

72 Porres JM: Jejunoileal bypass and psoriasis. Arch Dermatol 1977;113:983.

73 Farias MM, Achurra P, Boza C, Vega A, de la Cruz C: Psoriasis following bariatric surgery: clinical evolution and impact on quality of life on 10 patients. Obes Surg 2012;22:877-880.

74 De Menezes Ettinger JEMT, Azaro E, de Souza CAM, dos Santos Filho PV, Mello CAB, Neves $\mathrm{M}$, et al: Remission of psoriasis after open gastric bypass. Obes Surg 2006;16:94-97.

75 Higa-Sansone G, Szomstein S, Soto F, Brasecsco O, Cohen C, Rosenthal RJ: Psoriasis remission after laparoscopic Roux-en-Y gastric bypass for morbid obesity. Obes Surg 2004; 14:1132-1134.

76 Hossler EW, Maroon MS, Mowad CM: Gastric bypass surgery improves psoriasis. J Am Acad Dermatol 2011;65:198-200.

77 Upala S, Sanguankeo A: Effect of lifestyle weight loss intervention on disease severity in patients with psoriasis: a systematic review and meta-analysis. Int J Obes 2015;39:11971202.

78 Jensen P, Zachariae C, Christensen R, Geiker NRW, Schaadt BK, Stender S, et al: Effect of weight loss on the severity of psoriasis: a randomized clinical study. JAMA Dermatol 2013;149:795-801.

79 Jensen P, Christensen R, Zachariae C, Geiker NR, Schaadt BK, Stender S, et al: Long-term effects of weight reduction on the severity of psoriasis in a cohort derived from a randomized trial: a prospective observational followup study. Am J Clin Nutr 2016;104:259-265.

80 Naldi L, Conti A, Cazzaniga S, Patrizi A, Pazzaglia M, Lanzoni A, et al: Diet and physical exercise in psoriasis: a randomized controlled trial. Br J Dermatol 2014;170:634-642. 